University for Business and Technology in Kosovo

UBT Knowledge Center

Oct 28th, 4:00 PM - 5:50 PM

\title{
The effect of Particles PM10 and PM2.5 in dust emission of urban infrastructure from Thermal Power Plant Technology Kosovo
}

Afrim Syla

University for Business and Technology, afrim.syla@ubt-uni.net

Follow this and additional works at: https://knowledgecenter.ubt-uni.net/conference

Part of the Civil Engineering Commons

\section{Recommended Citation}

Syla, Afrim, "The effect of Particles PM10 and PM2.5 in dust emission of urban infrastructure from Thermal Power Plant Technology Kosovo" (2017). UBT International Conference. 40.

https://knowledgecenter.ubt-uni.net/conference/2017/all-events/40

This Event is brought to you for free and open access by the Publication and Journals at UBT Knowledge Center. It has been accepted for inclusion in UBT International Conference by an authorized administrator of UBT Knowledge Center. For more information, please contact knowledge.center@ubt-uni.net. 


\title{
The effect of Particles $\mathrm{PM}_{10}$ and $\mathrm{PM}_{2.5}$ industemission of urban infrastructure from Thermal Power Plant Technology Kosovo
}

\author{
Afrim Syla \\ UBT - Higher Education Institution Str. Lagjja KALABRIA p.n., 10000 Prishtinë, \\ Kosovë; \\ E-mail: afrim.syla@ubt-uni.net
}

\begin{abstract}
The main environmental problems in Kosovo include all issues related to water supply and sanitation system, air quality, solid waste management. The major problem remains high pollutions, energy losses and low collection efficiency. The awareness of environmental issues among the general public is poor.Air quality is degraded by various polluters, including traffic and two big thermal power plants which are located close to the surface lignite deposit in Obiliq. Emission of dust and ash from the thermo power plants exceeds by far the EU standards. Gas emissions have a high level of $\mathrm{PM}, \mathrm{CO}_{2}, \mathrm{SO}_{\mathrm{x}}, \mathrm{NO}_{\mathrm{x}}$. For coal generation, reducing non-GHG pollutant emissions $\left(\mathrm{SO}_{2}, \mathrm{NO}_{\mathrm{x}}, \mathrm{PM}\right)$ is significantly important. Additional problems are the ash hills that have more than 40 million tons of ash and are taking about 165 ha of agricultural land, as well as the pits created the coal extraction in the lignite open pit mines.
\end{abstract}

Keywords: industrial technology, air pollution, particulate matter, cyclone, electrostatic precipitators.

\section{Introduction}

Airborne particulate matter with aerodynamic diameters less than 10 microns (referred to as $\mathrm{PM}_{10}$ ) is one of the six criteria pollutants used by the U.S. Environmental Protection Agency as indicator of air quality. During the last decade, the health effects of urban aerosols have become a major concern for the society. At the same time, the radiation forcing by the natural and human-related aerosol particles has become a pressing concern when predicting global climatechange. In urban areas of developed countries, traffic is the largest single source of aerosol.

Kosovo currently wastes the majority of the electricity it produces in its two filthy lignite plants: 35 percent is lost through technical losses and theft and much more is wasted through lack of energy efficiency measures. Plans to build a new coal plant close to capital Prishtina have been around for over a decade, starting out as a planned $2000 \mathrm{MW}$ unit that would turn the country into the leading energy exporter for the Balkans. Yet, lack of investors and resistance to a massive lignite project in a country that already has the highest single point-source of carbon emissions in Europe have gradually diminished ambitions. While the plant is being depicted as necessary to ensure the country's energy security, 35 percent of electricity is lost in distribution (of which around 17 percent are technical and a result of an old grid and the other are commercial losses, i.e. theft), and much more is lost as a result of lack of energy efficiency measures in buildings. a range of alternatives exists to meet present supply constraints all at a lower cost than constructing a proposed $600 \mathrm{MW}$ coal plant. The options include energy efficiency measures, combinations of solar PV, wind, hydropower and biomass, and the 
introduction of natural gas. Concerns about costs have been heightened by the "Kosova e Re" project only receiving a single bid, which diminishes the likelihood of the Government getting good value for money.

\section{Pollution damage to health in urban infrastructure}

Kosovo currently has 835 early deaths per year and estimated direct costs of around EUR 100 million annually due to air pollution, of which the lignite plants are responsible for a substantial proportion. (Source: World Bank).However, far from solving this problem, a new lignite plant would perpetuate the health risks from coal for several more decades. Due to the location where the "Kosovo e Re" plant would be built, it is likely that emissions will exceed EU ambient air quality standards, even if "Kosovo B" and "Kosova e Re" meet EU emission standards. No reliable air quality monitoring is taking place, so it is difficult to prove that air quality would be acceptable with a new plant. Increased public awareness posed by global warming has led to greater concern over the impact of anthropogenic emissions from industrial production.

The dust particle emissions of PM2.5, PM10 and TPM have been the subject of claims and there is urgent need to minimize the increase in the emission levels by reducing the mass load emitted from the exhaust stacks. The particle concentrations are generally toxic and hazardous which can be a serious health risk to humans not limited to respiratory ailments (asthma, bronchitis, tuberculosis, etc), but also to the photosynthesis in plants. Tall stacks have traditionally been used to reduce ground level concentrations of air pollutants at minimum cost. Their effectiveness depends on height, velocity and temperature of the stack gases, and atmospheric conditions such as wind speed and direction, atmospheric stability, local topography and air quality as such serious environmental effects such as acid deposition and forest decline can occur in a sensitive receiving environments or remote locations. This lead to the development of an alternative air pollution control systems; such as wet scrubber systems, gravity separators, centrifugal collectors, fabric filters (bag house filters) cyclone and electrostatic precipitators (ESP) respectively.

\section{Dust Emission Separator in Air Pollution Control}

Cyclone is an air pollution control unit without any moving parts which separates dust emission from a gas stream by altering the inlet gas stream into a confined vortex. The unit is one of the most widely used separator in many industries and played important role in removing industrial dust from air or process gases. 


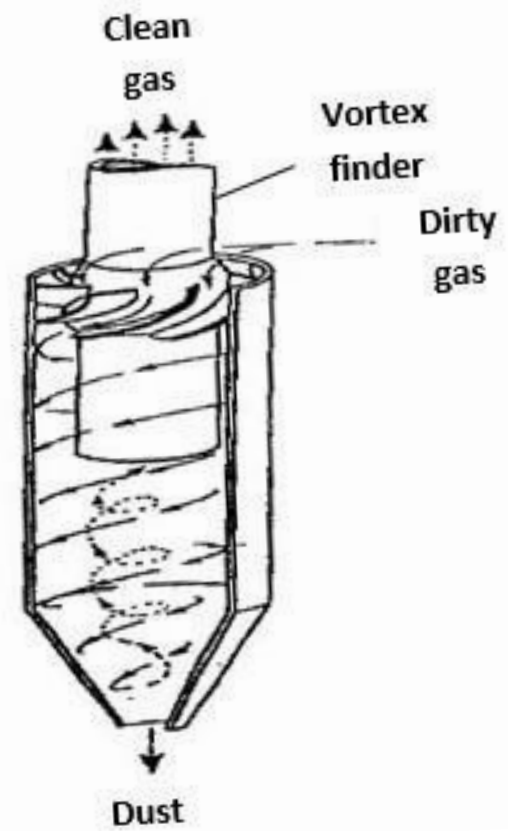

Figure 1 Cyclone with axial entry

\section{Methodology}

\section{Collection Efficiency of de Duster}

The cut diameter $\left(d_{p c}\right)$ is a semi-empirical relationship developed by LappleC.E.[1951], which referred to the size (diameter) of dust collected at $50 \%$ efficiency. The $d_{p c}$ is a convenient method in expressing the efficiency of a dust control device, which is shown (1) as follows:

$$
d_{p c}=[9 \mu W / 2(\rho p-\rho g)]^{1 / 2}
$$

where $\mu$ is the gas viscosity $\left(\mathrm{kg} / \mathrm{m}^{3}\right), W$ is the maximum radial distance of particulate $(\mathrm{m}), \mathrm{Ne}$ is the number of effective turns, $V i$ is the gas inlet velocity $(\mathrm{m} / \mathrm{s}), \rho g$ is the density of gas $\left(\mathrm{kg} / \mathrm{m}^{3}\right)$ and $\rho_{p}$ is the density of dust $\left(\mathrm{kg} / \mathrm{m}^{3}\right)$. The value of $W$ is difficult to obtain analytically and in this study, the $W$ value is obtained using a modification of Stairmand cyclone dimension with tangential entry based on same hydraulic diameter of axial and tangential entry Safikhani [2011]. Equations (2) and (3) are the tangential entry dimensions of a cyclone introduced by Stairmand [1991],

$$
\begin{aligned}
& D=W / 0.375 \\
& D=H / 0.75
\end{aligned}
$$


where $W$ is the width of tangential entry $(\mathrm{m}), H$ is the height of tangential entry (m) and $D$ is the diameter of cyclone body (m). Substitution of (2) into (3), will produce Equation (4) as follows

$$
H=2 W(4)
$$

The hydraulic diameter $\left(D_{H}\right)$ of tangential entry is referred to the $W$ and $H$ values as shown in Equation (5),

$$
D_{H}=2 H W / H+W
$$

Meanwhile, the hydraulic diameter $\left(D_{H}\right)$ of axial entry is referred to the $D \& D e$ values as shown in Equation (6),

$$
D_{H}=D-D e
$$

where $\mathrm{D}$ is the diameter of the body of the cyclone $(\mathrm{m})$ and $D e$ is the diameter of the vortex finder (m) as shown in Figure 2.

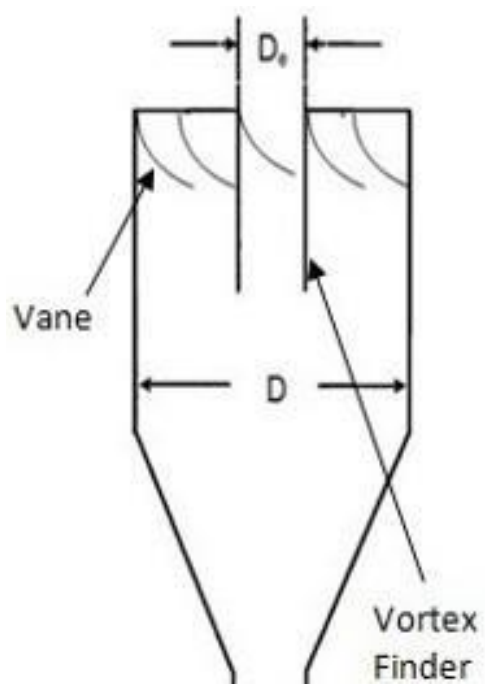

Figure 2 Schematic diagram of a miniature cyclone

Substitution of (4) and (5) into (6) will produce Equation (7) as shown below

$$
W=3 / 4(D-D e)
$$

Finally, substitution of (7) into (1) will generate the equation of cut diameter for axial entry as shown in Equation (8),

$$
d_{p c}=[27(D-D e) / 8(\rho p-\rho g)]^{1 / 2}
$$


According Frank R. S. and Nancy W. E. [2005], wet scrubbers have important advantage when compared to other air pollution control devices. The device can handle large volume of gases, can collect dust particulates like flammable and explosive dusts, foundry dusts, cement dusts and can absorb gaseous pollutants, acid mists, furnace fumes. The most common type of wet scrubbers are the spray tower scrubber, packed bed scrubber, mechanically aided scrubber, venture scrubber, etc. But cyclone described in Figure-1 is the simplest and low-cost. The dust particles are then separated from the gas stream and collected in a pool at the bottom of the chamber. A mist eliminator is usually placed at the top of the spray tower to remove both excess clean water droplets and dirty droplets which are very small and thus are carried upward by the gas flow. Although spray tower scrubbers are commonly used to remove particulate matters PM2.5, PM10, and PM as TPM and other pollutants as presented in Afrim S, PhD [2009]. However, the exact mechanisms governing the optimum particleremoval efficiency of the system in relation to the liquid droplet size and the liquid to gas ratio and the performance of the system based on the air quality standards are not fully described. The objective of the present study is to promote a better understanding of the sub-micron dust particle removal characteristics of spray tower scrubber system by analytically exploring the design of the system using data obtained from coal industry (Table-1), investigate the effect of droplet size and liquid to gas ratio on the removal efficiency of the scrubber system and evaluate the performance of the system using predicted values of the particle removal efficiency by considering the World Health Organizations (WHO) air quality standard for PM10.

Table-1. Exhaust particle-laden gas data.

Parameters Specifications

Volume flow rate

$29.13 \mathrm{~m}^{3} / \mathrm{s}$

Mass flow rate

$33.08 \mathrm{~kg} / \mathrm{s}$

Gas density

$0.82 \mathrm{~kg} / \mathrm{m}^{3}$

Dust burden (Concentration)

$22,859 \mu \mathrm{g} / \mathrm{m}^{3}$

\section{Combustion of Coal and Dust Emission}

Table 1 indicates that the combustion of coal is one of the major industrial sources of particulates across several size ranges and within two source sectors, Power stations and other industry.

Particulate emissions from combustion of coal at large combustion plant have been regulated for many years. Major combustion installations provide estimates of annual PM10 emissions to the Kosovo regulatory authorities.

The Other Industry sector PM10 emission estimates for the 2012 based on a USEPA[2011] emission factor for stoker-fired boilers. This factor is considered to have a high uncertainty for this broad sector which includes a wide range of combustion technologies and plant size. However, the PM10 factor has not been considered in this task as it is addressed elsewhere in this project.

The current sub-PM10 emissions is very high This provides a speciation profile for the PM10, PM2.5 and PM1.0 species for the combustion of coal using ESP (electrostatic precipitators and cyclone) as abatement technology. Almost all major Kosovo coal-fired power stations have ESPs for particulate abatement, two stations also have Flue Gas Desulphurisation scrubbers, cyclones and one station (currently in receivership) has fabric filters. Other Industry sources include a range of abatement techniques however. The present environmental situation in 
Prishtina, put as in front of the responsibility to act more rationally towards nature and to be more responsible towards the protection of the environment for future generations.

\section{Air quality and Pollution Control}

The lack of protection of the environment during the last 15 years, as well as the conflict in Kosovo is the origin of huge problems regarding present environmental situation in Kosovo. Urban air contains dust particles and gases, added on it is as results of normal activity of the city and industries in them. Exposure to airborne particulates $\mathrm{PM}_{10}$ and $\mathrm{PM}_{2.5}$ containing low concentrations of heavy metals, such as Lead $(\mathrm{Pb})$, may have serious health effects. However, little is known about the specification and particle size of these airborne metals. Fine and $\mathrm{PM}_{10}$ particles size in aerosol samples from the Prishtina urban area were exanimate in detail to investigate metal concentrations and speciation.

Sampling of suspended particulate matter, $\mathrm{PM}_{10}$ and $\mathrm{PM}_{2.5}$ started in July April 2015 and are still in progress at three sites in the very urban area of Prishtina and Mitrovica. Suspended particles were collected on Pure Teflon filters, Whitman ( $37 \mathrm{~mm}$ diameter, $2 \mu \mathrm{m}$ pore size) and Pure Quartz, Whitman (37 mm diameter) filter paper, using the low volume air sampler MiniVole Air metrics Co, Inc.(5 $1 \mathrm{~min}^{-1}$ flow rate). The duration of each sampling period was 24 hours. The filter samples were sealed in plastic bags and kept in portable refrigerators, in horizontal position during transport back to the laboratory. Particle mass was gravimetrically determined by weighting loaded and unloaded filters, after 48 hours conditioning in a desiccators, in clean room class at the temperature $\mathrm{T}=20{ }^{\circ} \mathrm{C}$ and constant relative humidity $\mathrm{RH}$ around $50 \%$.

Kosovo needs to increase renewable - energy efficiency and decrease dust with $\mathrm{CO2}$ emissions

By 2020, Kosovo has committed through the Energy Community to source 25 percent of overall energy from renewable sources and improve energy efficiency by 9 percent. And as the country is aiming to join the $\mathrm{EU}$, it will have to adhere to ever stricter $\mathrm{CO} 2$ reduction targets (likely to be $80-95$ percent for the EU as a whole by 2050). This one coal power plant alone will likely swallow up most of the country's carbon budget by 2050, leaving a choice between closing the plant earlier than planned or paying penalties.From the World Health Organization's, WHO annual and 24 hour mean air quality standard for PM10, the dust particle concentration must not exceed an annual mean of $20 \mu \mathrm{g} / \mathrm{m} 3$ and a 24 -hour mean of $50 \mu \mathrm{g} / \mathrm{m} 3$. Considering this, a model which relates the particulate collection efficiency and the concentration of the dust particle entering the scrubber (dust laden) and the WHO [2005] air quality standard concentration was used.

\section{Conclusions}

The proposed system can be used in controlling air quality - particle sizes of $5 \mu \mathrm{m}$ and $10 \mu \mathrm{m}$ that are emitted from industrial productions. It is expected that the information provided in this paper will be useful for engineers and researchers for many air pollution control applications especially in the areas of particulate matter ( $\left.\mathrm{PM}_{10}\right)$ emissions. The study also showed that the predicted pressure drop of de-Duster was the lowest compared with other conventional cyclones suggesting of its ability reducing the operational cost of the system. 


\section{References}

1. Afrim S. 2009. Air pollution characterisation in Mitrovica and Prishtina with particulate matter and their trait dispersion.

2. Frank R. S. and Nancy W. E. 2005. Environmental Engineers Mathematics Handbook. CRC Press, Florida, USA. pp. 208-249.

3. Benitez, J. 1993. Process Engineering and Design for Air Pollution Control. New Jersey: PTR Prentice Hall.

4. Lapple, C.E. 1951. Process use many collector types. Chemical Engineering 58(5): 175183.

5. .Leith, D. \& Licht, W. 1996. The Collection Efficiency of Cyclone Type Particle Collectors: A New Theoretical Approach. AIChE Symp. Ser. Air Pollut. Control.

6. Norelyza, H. and M. R. 2013. Performance of de-Duster on Particulate Emission Control for A Different Area of Axial Entry. Journal of Environmental Research and Development. 7(4): 1392-1398.

7. Rongbiao, X., Park, S.H. \& Lee, K.W. 2001. Effects of cone dimension on cyclone performance. Aerosol Science 32: 549-561.

8. Stairmand, C.J. 1951. The Design and Performance of cyclone Separators, Transactions of Industrial Chemical Engineers. 29: 356-383

9. US EPA, Environmental Protection Agency. 2011. Design Evaluation of Particulate Wet Scrubber System. SI 412C Module 10, 10-3

10. WHO, [2005] World Health Organization ; Air quality 